\title{
Effects of Epidermal Growth Factor on Glutamine and Glucose Absorption by IPEC-J2 Cells Challenged by Lipopolysaccharide using the Ussing Chamber System
}

\author{
Xiaopeng Tang ${ }^{1,2 *}$ and Kangning Xiong ${ }^{1,2}$ \\ ${ }^{1}$ School of Karst Science, Guizhou Normal University, Guiyang, China \\ ${ }^{2}$ State Key Laboratory Cultivation for Karst Mountain Ecology Environment of Guizhou \\ Province, Guiyang, China
}

\section{A B S T RA C T}

The aim of this study was to investigate the effects of epidermal growth factor (EGF) on glutamine and glucose absorption of IPEC-J2 cells using the Ussing chamber system. Cells were treated with: (1) EGF $(0 \mathrm{ng} / \mathrm{mL})+\mathrm{LPS}(0 \mu \mathrm{g} / \mathrm{mL})$ (Control group), (2) EGF (100 ng / mL) + LPS $(0 \mu \mathrm{g} / \mathrm{mL})$ (EGF group), (3) EGF $(0 \mathrm{ng} / \mathrm{mL})+$ LPS $(1 \mu \mathrm{g} / \mathrm{mL})$ (LPS group), and (4) EGF $(100 \mathrm{ng} / \mathrm{mL})+\mathrm{LPS}(1 \mu \mathrm{g} / \mathrm{mL})$ (EGF+LPS group) for $24 \mathrm{~h}$ for ussing chamber assay. The transepithelial electrical resistance (TEER, $\Omega . c \mathrm{~m} 2)$, glutamine and glucose absorption rate (\%) were measured. The results showed that: (1) EGF significantly $(P<0.05)$ increased the TEER of TPEC-J2 cells induced by LPS; $(2)$ EGF significantly $(P$ $<0.05$ ) increased the absorption of glucose and glutamine of IPEC-J2 cells induced by LPS. It can be speculate that EGF repaired the injured cells by reducing cell permeability and increasing the absorption of glutamine and glucose.
\end{abstract}

\section{INTRODUCTION}

$\mathrm{G}$ lutamine is one of the most abundant amino acid In blood, which is an important precursor in the biosynthetic process of proteins, nucleic acids, glucose, amino sugars, and the main source of energy for intestinal epithelial cells (Huang et al., 2007; Pochini et al., 2014). Glucose is the main carbon and energy source of eukaryotic cells, and glucose transport to mammalian cells is the rate-limiting step in glucose utilization (Chaudhry et al., 2012). The transport of glucose, glutamine and other nutrients through the intestinal mucosa from the gastrointestinal tract to the epithelial cells is crucial for the growth and development of animals. Epidermal growth factor (EGF), a small mitogenic polypeptide comprising 53 amino acid residues, has been established as a trophic factor for the epithelial cell homeostasis (Tang et al., 2016, 2018) and nutrients transport in the small intestine (Huang et al., 2007; Trapani et al., 2014; Wang et al., 2019). Although, previous studies have demonstrated that EGF had a positive effect on the absorption of glutamine (Huang et al., 2007) and glucose (Xu et al., 2015; Wang et al., 2019). However, the studies of the effects of EGF

\footnotetext{
Corresponding author: tangxiaopeng110@126.com 0030-9923/2021/0002-0417\$9.00/0

Copyright 2021 Zoological Society of Pakistan
}

\begin{tabular}{l} 
Article Information \\
Received 17 January 2020 \\
Revised 14 February 2020 \\
Accepted 20 February 2020 \\
Available online 07 January 2021 \\
Authors' Contribution \\
\hline XT conducted the experiment, \\
analyzed the data, wrote the article \\
and provided the financial support \\
for this study. KX helped in the \\
experimental design and participated \\
in data analyzed. \\
Key words \\
Epidermal growth factor, Glucose, \\
Glutamine, IPEC-J2 cells, Ussing \\
chamber
\end{tabular}

on absorption of glutamine and glucose under stress conditions were rarely reported.

The Ussing chamber system is consists of a circuit system, diffusion chambers, inserts, electrodes and a data collection system (He et al., 2013), which provides a simple, but powerful technique for measuring the transport of ions (Muscher et al., 2012), drugs (Sjoberg et al., 2013) and nutrients (Albin et al., 2007) across intestinal epithelial tissues. There are published studies involving in the use of Ussing chambers to evaluate the absorption of glucose in small intestine of animals (Millar et al., 2002; Awad et al., 2013). However, the studies of the effects of EGF on absorption of glutamine and glucose under stress conditions using Ussing chamber are lacking. Therefore, the aim of the present study was to investigate the effect of EGF on glutamine and glucose absorption of IPEC-J2 cells induced by lipopolysaccharide (LPS), a endotoxin usually used to establish cellular injure model, using the Ussing chamber system.

\section{MATERIALS AND METHODS}

\section{Cell culture}

Porcine intestinal epithelial cells (IPEC-J2) were kindly provided by Dr. Bie Tan (Institute of Subtropical Agriculture, Chinese Academy of Science, Changsha, China). IPEC-J2 cells were cultured in DMEM / F12 
medium (GE Healthcare life sciences, South Logan, Utah, USA) containing 10\% FBS (GIBCO, Carlsbad, CA, USA), $1 \%$ antibiotics (Penicillin-Streptomycin) (GIBCO, Carlsbad, CA, USA), and grown in a humidified incubator at $37^{\circ} \mathrm{C}$ with $5 \% \mathrm{CO} 2$ and $95 \%$ air as previously described (Tang et al., 2018). After $80 \%$ of fusion, cells digested with $0.25 \%$ trypsin-EDTA (GIBCO, Carlsbad, CA, USA). Then, the cells $\left(2 \times 10^{5} /\right.$ well $)$ were transferred to Transwell (Coring Inc., Coming, NY, USA), and cultured for 21-24 days until the cells naturally differentiated into a polar monolayer.

\section{Cell treatment}

Removed the medium in the culture plate, and washed the cells in Transwell for three times with D-Hanks (Solarbio, Beijing, China). The IPEC-J2 cells were treated with: (1) EGF $(0 \mathrm{ng} / \mathrm{mL})+$ LPS $(0 \mu \mathrm{g} / \mathrm{mL})$ (Control group), (2) EGF (100 ng / mL) + LPS (0 $\mu \mathrm{g} / \mathrm{mL})$ (EGF group), (3) EGF $(0 \mathrm{ng} / \mathrm{mL})+$ LPS $(1 \mu \mathrm{g} / \mathrm{mL})$ (LPS group), and (4) EGF $(100 \mathrm{ng} / \mathrm{mL})+\operatorname{LPS}(1 \mu \mathrm{g} / \mathrm{mL})($ EGF+LPS group $)$ for $24 \mathrm{~h}$. EGF was purchased from Peprotech (Rocky Hill, NJ, USA). LPS was purchased from Sigma-Aldrich (Saint Louis, MO, USA). The EGF and LPS concentration were adopted according to Tang et al. (2018).

\section{Ussing chamber assay}

After a $24 \mathrm{~h}$ of incubation, the membrane in Transwell was took out carefully for Ussing chamber assay (VCC MC6, Physiologic Instruments, Inc., San Diego, CA, USA). The operating procedure of Ussing chamber was conducted as previously described. Briefly, the membrane was mounted between the two halves of Ussing chambers inserts, which the polar side towards to mucosal compartments and the non-polar side towards to serosal compartments. Each compartment filled with $4 \mathrm{~mL}$ HepesTris buffer $(6 \mathrm{~g}$ Hepes, $5.4 \mathrm{mM} \mathrm{KCl}, 1.8 \mathrm{mM} \mathrm{CaCl} 2,0.8$ $\mathrm{mM} \mathrm{MgSO} 4,8.18 \mathrm{~g} \mathrm{NaC1}$, adjust the $\mathrm{pH}$ to 7.4 using $1 \mathrm{M}$ Tris), circulated with carbogen gas $(95 \% \mathrm{O} 2,5 \% \mathrm{CO} 2)$ at a temperature of $37^{\circ} \mathrm{C}$. After an equilibration period of 10 min, $1 \mathrm{~mL}$ of $1 \mathrm{~mol} / \mathrm{L}$ glutamine or glucose solutions was added into mucosal compartment, and $1 \mathrm{~mL}$ of $1 \mathrm{~mol} / \mathrm{L}$ mannitol solution was added into serosal compartment. After $45 \mathrm{~min}$ of incubation, $0.5 \mathrm{~mL}$ of samples was collected from both compartments for glutamine or glucose concentration analysis. The determination of glutamine concentration was use a Glutamine measurement kit (Nanjing Jiancheng Bioengineering Institute, Nanjing, China) according to the instructions of the manufacturer. The determination of glucose concentration was use a Glucose Assay Kit (Nanjing Jiancheng Bioengineering Institute, Nanjing, China) according to the instructions of the manufacturer. During the experiment, TEER was monitored during the whole experimental period using a computer controlled voltage clamp device (Physiologic Instruments Inc., San Diego, CA, USA). Experiments were performed in six times. The absorption rate of glutamine and glucose was calculated by following equations:

Gln absorption rate $(\%)=($ TGln - SGln - MGln $) /$ TGln

Where Gln, glutamine; TGln, total Gln content; SGln, the Gln content in serosal compartment; and MGln, the Gln content in mucosal compartment.

Glu absorption rate $(\%)=($ TGlu - SGlu - MGlu $) /$ TGlu

Where Glu, glucose; TGlu, total Glu content; SGlu, the Glu content in serosal compartment; and MGlu, the Glu content in mucosal compartment.

\section{Statistical analysis}

All data were expressed as mean \pm standard deviation (SD). Data were performed by one-way ANOVA procedure of SPSS 21.0 software (SPSS, Inc., Chicago, IL, USA). Differences among treatment mean were determined using Duncan's multiple comparison test. $P<0.05$ was considered significant.

\section{RESULTS AND DISCUSSION}

\section{Effects of EGF on TEER in IPEC-J2 induced by LPS}

The intestinal epithelium is formed by a continuous monolayer of proliferating and differentiating intestinal epithelial cells (IECs), which forms a selective barrier that allows nutrients absorption and defends against toxins, allergens, and pathogens from the gut lumen into mucosal tissue (Tang et al., 2016). Disruption of the intestinal epithelial homeostasis has been reported to increase intestinal permeability, which cause numerous gastrointestinal diseases ( $\mathrm{Yu}$ and $\mathrm{Li}, 2014)$. Thus, the normal regeneration and integrity of epithelial cells in the small intestine is important for maintaining intestinal health, and is the structural basis for the absorption of nutrients for animals. Transepithelial electrical resistance (TEER) cans reflect the cells permeability of intestine, which could be used as an important index to evaluate intestinal injury, and has been mainly applied for assessing the permeability of tight junctions or the membrane perturbation by toxicants on intestinal epithelium (Chen et al., 2015; Garcia-Hernandez et al., 2015). The Ussing chamber model is one of in vitro methods to measure TEER (He et al., 2013). In the present study, the effect of EGF on TEER in IPEC-J2 induced by LPS was showed in Figure 1. The results showed that, EGF and LPS had significantly $(P<0.05)$ effects on TEER of IPEC-J2 cells. EGF significantly $(P<0.05)$ increased the TEER of cells, and LPS significantly $(P<0.05)$ decreased the TEER of cells compared to other treatments. While, cells treated 
with EGF plus LPS significantly $(P<0.05)$ increased the TEER compared to cells treated LPS, and has no difference compared to Control group. It indicated that EGF has a protective effect on IPEC-J2 cells injured by LPS. Previous studies had confirmed the protective effects of EGF acted in intestinal homeostasis, which EGF significantly reduced the LDH release and apoptosis of intestinal epithelial cells (Tang et al., 2018), and significantly increased the TEER and decrease epithelial paracellular permeability (Basuroy et al., 2006; Flores-Benitez et al., 2009; Garcia-Hernandez et al., 2015). The present study also confirmed that EGF could increase the TEER of IPEC-J2 cells, which consistent with the results of Tang et al. (2018), indicated that EGF plays an important role in maintaining intestinal integrity.

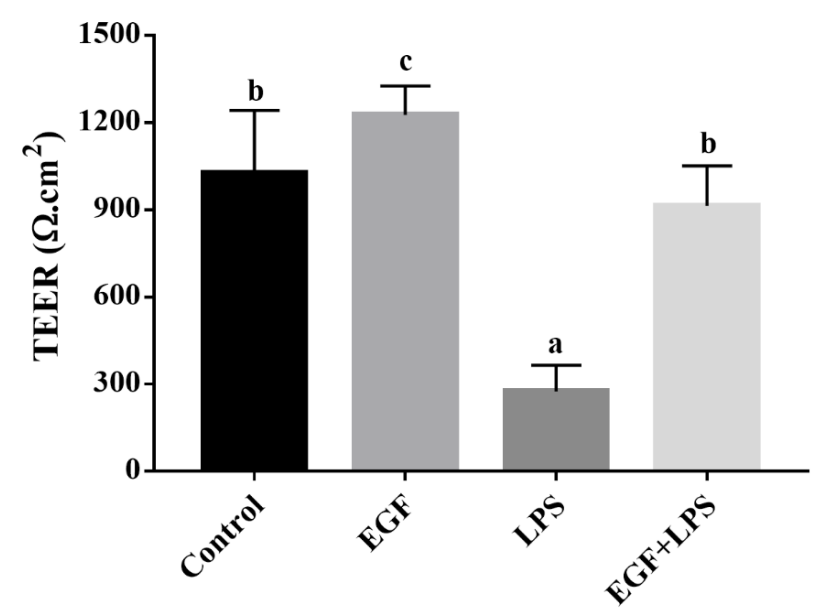

Fig. 1. Effects of EGF on TEER of IPEC-J2 cells induced by LPS. TEER, transepithelial electrical resistance; EGF, epidermal growth factor; LPS, lipopolysaccharide; a, b, $\mathrm{c}$ means different lowercase letters indicate significant differences $(P<0.05)$.

Effect of EGF on glutamine absorption in IPEC-J2 cells induced by LPS

Glutamine is the main source of energy for intestinal epithelial cells and lymphocytes (Huang et al., 2007; Pochini et al., 2014). The absorption of glutamine is crucial for the cell survival, proliferation and differentiation (Xing et al., 2017; Bernard et al., 2018). In the present study, we used the Ussing chamber system to measure the effect of EGF on the absorption of glutamine in IPEC-J2 cells, the results are presented in Figure 2. The results showed EGF had a positive effect on glutamine absorption of IPEC-J2 cells. Cells treated with EGF significantly $(P<$ 0.05 ) promoted glutamine absorption compared to Control group. LPS had a negative effect on glutamine absorption in IPEC-J2 cells. The glutamine absorption rate in the LPS-treated group was significantly $(P<0.05)$ lower than that in the Control group. In vivo and in vitro studies have shown that EGF can promote the absorption of glutamine in intestinal epithelial cells by increasing $\mathrm{Na}+$-dependent neutral amino acid transporter (ASCT2) expression and ASCT2 transport activity, a broad-spectrum amino acid transporter, in intestinal epithelial cells (Ray et al., 2005; Huang et al., 2007; Avissar et al., 2008). The present study also confirmed that EGF could promote the absorption of glutamine in intestinal epithelial cells. While, LPS, a major integral component of the outer membrane of gram-negative bacteria, which can induce cell injury severely (Talavera et al., 2015; Tang et al., 2018), made the cell permeability increased, finally resulted a decreased nutrients absorption function. The present study showed that EGF plus LPS group had a higher $(P<0.05)$ glutamine absorption rate than that LPS treated group, although significantly $(P<0.05)$ lower than EGF treated group, but had no difference between the Control group. The results from the present study indirectly indicated that EGF had a function on repairing the damaged cells. This is because, in theory, during the repairing process, organs need more energy to meet the energy needs of cell proliferation and differentiation.

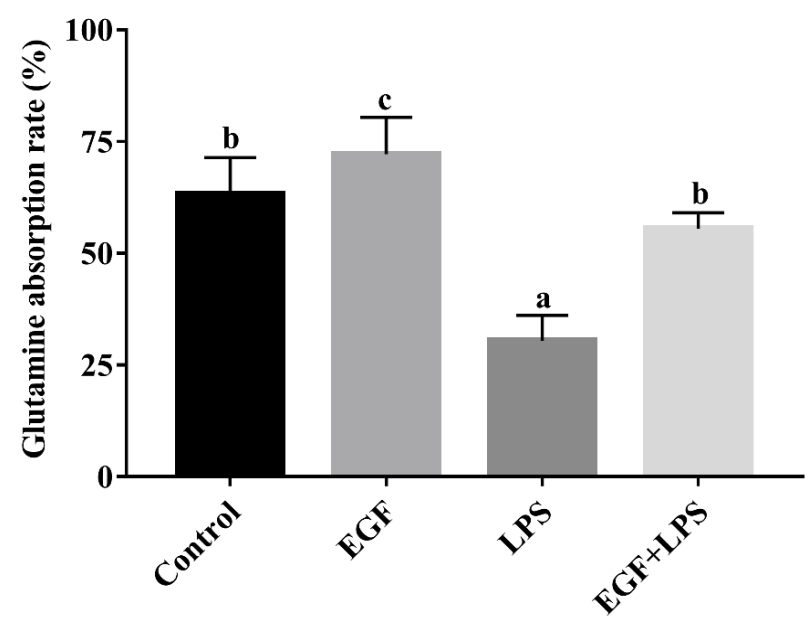

Fig. 2. Effects of EGF on glutamine absorption of IPEC-J2 cells induced by LPS. EGF, epidermal growth factor; LPS, lipopolysaccharide; a, b, c means different lowercase letters indicate significant differences $(P<0.05)$.

Effect of EGF on glucose absorption in IPEC-J2 cells induced by LPS

The effect of EGF on glucose absorption in IPEC-J2 cells induced by LPS is presented in Figure 3. The results showed that EGF significantly $(P<0.05)$ increased glucose absorption, and LPS significantly $(P<0.05)$ decreased glucose absorption, EGF plus LPS group had a higher $(P<$ $0.05)$ glucose absorption rate than that LPS treated group, although significantly $(P<0.05)$ lower than EGF treated 
group, but had no difference between the control group, which is consistent with glutamine absorption. Glucose is the main carbon and energy source of eukaryotic cells, there were at least two glucose transporters, sodium/glucose cotransporter 1 (SGLT1), and glucose transporter 2 (GLU2), have been shown to be involved in glucose transport (Bedford et al., 2015; Xu et al., 2015; Huerzeler et al., 2020). SGLT1, a high affinity and low transport capacity glucose transporter is mainly mediates glucose transport across the brush border membrane of the small intestine (Wang et al., 2015; Bedford et al., 2015). GLU2, a low affinity and high transport capacity glucose transporter, can mediate the intracellular glucose transporter to portal vein (Chaudhry et al., 2012; Zheng et al., 2012). The up-regulated expression of SGLT1 can increase glucose absorption and improve energy level (Song et al., 2010). Previous studies have shown that EGF could promote the absorption of intestinal glucose by upregulating the expression of SGLT1 (Cellini et al., 2005; Bedford et al., 2015; Xu et al., 2015). However, the effect of EGF on the expression of GLU2 is controversial. Bedford et al. (2015) showed that EGF had no effect on GLUT2 mRNA expression in weaned piglets, while, Xu et al. (2015) and Wang et al. (2019) showed that EGF could promote the expression of GLUT2 mRNA in weaned piglets. Therefore, though, the present studies have demonstrated EGF can promote the absorption of glucose, it cannot clarify what way EGF to promote the glucose absorption, the further research is needed.

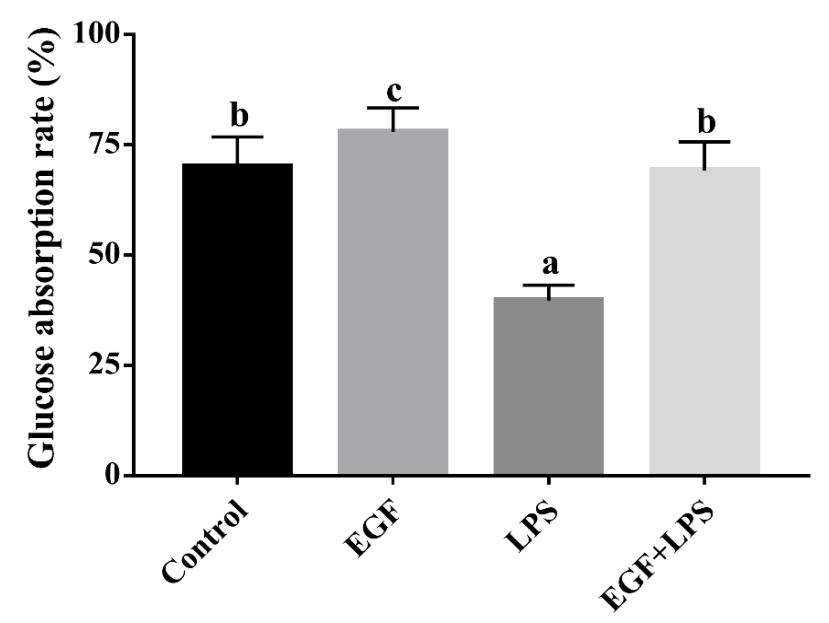

Fig. 3. Effects of EGF on glucose absorption by IPEC-J2 cells induced by LPS. EGF, epidermal growth factor; LPS, lipopolysaccharide; a, b, c means different lowercase letters indicate significant differences $(P<0.05)$.

\section{CONCLUSIONS}

In summary, the results of the present study suggested that EGF could enhance the TEER and promote the absorption of glucose and glutamine by IPEC-J2 cells induced by LPS. It can be speculated that EGF repaired injured cells by reducing cell permeability and increasing the absorption of glutamine and glucose.

\section{ACKNOWLEDGEMENTS}

This research was supported by grants from the Doctoral Launched Scientific Research Program of Guizhou Normal University GZNUD (2018)26).

Statement conflict of interest statement

The authors have declared no conflict of interest.

\section{REFERENCES}

Albin, D.M., Wubben, J.E., Rowlett, J.M., Tappenden, K.A. and Nowak, R.A., 2007. Changes in small intestinal nutrient transport and barrier function after lipopolysaccharide exposure in two pig breeds. J. Anim. Sci., 85: 2517-2523. https://doi. org/10.2527/jas.2006-237

Avissar, N.E., Sax, H.C. and Tola, L., 2008. In human entrocytes, GLN transport and ASCT2 surface expression induced by short-term EGF are MAPK, PI3K, and Rho-dependent. Dig. Dis. Sci., 53: 21132125. https://doi.org/10.1007/s10620-007-0120-y

Awad, W.A., Ghareeb, K., Paßlack, N. and Zentek, J., 2013. Dietary inulin alters the intestinal absorptive and barrier function of piglet intestine after weaning. Res. Vet. Sci., 95: 249-254. https://doi. org/10.1016/j.rvsc.2013.02.009

Basuroy, S., Seth, A., Elias, B., Naren, A.P. and Rao, R., 2006. MAPK interacts with occludin and mediates EGF-induced prevention of tight junction disruption by hydrogen peroxide. Biochem. J., 393: 69-77. https://doi.org/10.1042/BJ20050959

Bedford, A., Chen, T., Huynh, E., Zhu, C., Medeiros, S., Wey, D., de Lange, C. and Li, J., 2015. Epidermal growth factor containing culture supernatant enhances intestine development of early-weaned pigs in vivo: potential mechanisms. J. Biotechnol., 196: 9-19. https://doi.org/10.1016/j. jbiotec.2015.01.007

Bernard, K., Logsdon, N.J., Benavides, G.A., Sanders, Y., Zhang, J., Darley-Usmar, V.M. and Thannickal, V.J., 2018. Glutaminolysis is required for transforming growth factor- $\beta 1$-induced 
myofibroblast differentiation and activation. J. biol. Chem., 293: 1218-1228. https://doi.org/10.1074/ jbc.RA117.000444

Cellini, C., Xu, J. and Buchmiller-Crair, T., 2005. Effect of epidermal growth factor on small intestinal sodium/glucose cotransporter-1 expression in a rabbit model of intrauterine growth retardation. J. Pediatr. Surg., 40: 1892-1897. https://doi. org/10.1016/j.jpedsurg.2005.08.049

Chaudhry, R.M., Scow, J.S., Madhavan, S., Duenes, J.A. and Sarr, M.G., 2012. Acute enterocyte adaptation to luminal glucose: a posttranslational mechanism for rapid apical recruitment of the transporter glut2. J. Gastrointest. Surg., 16: 312-319. https://doi. org/10.1007/s11605-011-1752-y

Chen, S., Einspanier, R. and Schoen, J., 2015. Transepithelial electrical resistance (TEER): a functional parameter to monitor the quality of oviduct epithelial cells cultured on filter supports. Histochem. Cell Biol., 144: 509-515. https://doi. org/10.1007/s00418-015-1351-1

Flores-Benitez, D., Rincon-Heredia, R., Razgado, L.F., Larre, L., Cereijido, M. and Contreras, R.G., 2009. Control of tight junctional sealing: roles of epidermal growth factor and prostaglandin E2. Am. J. Physiol. Cell. Physiol., 297: C611-C620. https:// doi.org/10.1152/ajpcell.00622.2008

Garcia-Hernandez, V., Flores-Maldonado, C., RinconHeredia, R., Verdejo-Torres, O., Bonilla-Delgado, J., Meneses-Morales, I., Gariglio, P. and Contreras, R.G., 2015. EGF regulates claudin-2 and-4 expression through Src and STAT3 in MDCK cells. J. Cell. Physiol., 230: 105-115. https://doi. org/10.1002/jcp. 24687

He, L., Yin, Y., Li, T., Huang, R., Xie, M., Wu, Z. and $\mathrm{Wu}, \mathrm{G} ., 2013$. Use of the Ussing chamber technique to study nutrient transport by epithelial tissues. Front. Biosci., 18: 1266-1274. https://doi. org/10.2741/4178

Huang, Q., Li, N., Zhu, W., Li, Q. and Li, J., 2007. Glutamine transporter ASCT2 was down-regulated in ischemic injured human intestinal epithelial cells and reversed by epidermal growth factor. $J$. Parenter. Enteral. Nutr., 31: 86-93. https://doi. org/10.1177/014860710703100286

Huerzeler. N., Petkovic, V., Sekulic-Jablanovic, M., Kucharava, K., Wright, M.B. and Bodmer, D., 2020. Insulin receptor and glucose transporters in the mammalian cochlea. Audiol. Neurootol., 24: 65-76. https://doi.org/10.1159/000499561

Millar, G.A., Hardin, J.A., Johnson, L.R. and Gall, D.G., 2002. The role of PI3-kinase in EGF-stimulated jejunal glucose transport. Can. J. Physiol. Pharm., 80: 77-84. https://doi.org/10.1139/y02-012

Muscher, A.S., Wilkens, M.R., Nina, M., Schröder, B., Breves, G. and Huber, K., 2012. Ex vivo intestinal studies on calcium and phosphate transport in growing goats fed a reduced nitrogen diet. $B r . J$. Nutri., 108: 628-637. https://doi.org/10.1017/ S0007114511005976

Pochini, L., Scalise, M., Galluccio, M. and Indiveri, C., 2014. Membrane transporters for the special amino acid glutamine: structure/function relationships and relevance to human health. Front. Chem., 2: 61. https://doi.org/10.3389/fchem.2014.00061

Ray, E.C., Avissar, N.E. Salloum, R. and Sax, H.C., 2005. Growth hormone and epidermal growth factor upregulate specific sodium-dependent glutamine uptake systems in human intestinal C2BBe1 cells. J. Nutr., 135: 14-18. https://doi. org/10.1093/jn/135.1.14

Sjoberg, A., Lutz, M., Tannergren, C., Wingolf, C., Borde, A. and Ungell, A.L., 2013. Comprehensive study on regional human intestinal permeability and prediction of fraction absorbed of drugs using the Ussing chamber technique. Eur. J. Pharm. Sci., 48: 166-180. https://doi.org/10.1016/j. ejps.2012.10.007

Song, X., Xu, J., Wang, T. and Liu, F., 2010. Traditional Chinese medicine decoction enhances growth performance and intestinal glucose absorption in heat stressed pigs by up-regulating the expressions of SGLT1 and GLUT2 mRNA. Livest. Sci., 128: 75-81. https://doi.org/10.1016/j.livsci.2009.11.002

Talavera, M.M., Kralik, N., Jin, Y., Chen, B., Liu, Y. and Nelin, L.D., 2015. Mitogen-activated protein kinase phosphatase-1 prevents lipopolysaccharideinduced apoptosis in immature rat intestinal epithelial cells. Pediatr. Res., 78: 128-136. https:// doi.org/10.1038/pr.2015.88

Tang, X., Liu, B., Wang, X., Yu, Q. and Fang, R., 2018. Epidermal growth factor, through alleviating oxidative stress, protect IPEC-J2 cells from lipopolysaccharides-induced apoptosis. Int. J. mol. Sci., 19: 848. https://doi.org/10.3390/ijms19030848

Tang, X., Liu, H., Yang, S., Li, Z., Zhong, J. and Fang, R., 2016. Epidermal growth factor and intestinal barrier function. Mediat. Inflamm., 2016: 1927348. https://doi.org/10.1155/2016/1927348

Trapani, V., Arduini, D., Luongo, F. and Wolf, F.I., 2014. EGF stimulates $\mathrm{Mg} 2+$ influx in mammary epithelial cells. Biochem. biophys. Res. Commun., 454: 572575. https://doi.org/10.1016/j.bbrc.2014.10.125

Wang, C.W., Chang, W.L., Huang, I.C., Chou, F.C., 
Chan, F.N., Su, S.C., Huang, S.F., Ko, H.H., Ko, Y.L., Lin, H.C. and Chang, T.C., 2015. An essential role of cAMP response element-binding protein in epidermal growth factor-mediated induction of sodium/glucose cotransporter1 gene expression and intestinal glucose uptake. Int. J. Biochem. Cell Biol., 64: 239-251. https://doi.org/10.1016/j. biocel.2015.04.006

Wang, L., Zhu, F., Yang, H., Zhong, J., Li, Y., Ding, X., Xiong, X. and Yin, Y., 2019. Effects of dietary supplementation with epidermal growth factor on nutrient digestibility, intestinal development and expression of nutrient transporters in early-weaned piglets. J. Anim. Physiol. Anim. Nutr., 103: 618625. https://doi.org/10.1111/jpn.13059

Xu, S., Wang, D., Zheng, P., Lin, Y., Fang, Z., Che, L. and Wu, D., 2015. Oral administration of Lactococcus lactis-expressed recombinant porcine epidermal growth factor (rpEGF) stimulates the development and promotes the health of small intestines in earlyweaned piglets. J. appl. Microbiol., 119: 225-235. https://doi.org/10.1111/jam.12833

Yu, Y.B. and Li, Y.Q., 2014. Enteric glial cells and their role in the intestinal epithelial barrier. World J. Gastroenterol., 20: 11273-11280. https://doi. org/10.3748/wjg.v20.i32.11273

Zheng, Y., Scow, J.S., Duenes, J.A. and Sarr, M.J., 2012. Mechanisms of glucose uptake in intestinal cell lines: role of GLUT2. Surgery, 151: 13-25. https:// doi.org/10.1016/j.surg.2011.07.010

Xing, S., Zhang, B., Lin, M., Zhou, P., Li, J., Zhang, L., Gao, F. and Zhou, G., 2017. Effects of alanylglutamine supplementation on the small intestinal mucosa barrier in weaned piglets. Asian-Australas. J. Anim. Sci., 30: 236-245. https://doi.org/10.5713/ ajas.16.0077 